\section{Phonemic and semantic generation norms}

\author{
KEITH D. HORTON \\ Wilfrid Laurier University, Waterloo, Ontario N2L 3C5, Canada
}

Independent groups of subjects generated restricted free associations that either rhymed with the cue or were members of the semantic category designated by the cue. The data include both a listing of the responses to each cue and a cross-index of all words appearing as responses to more than one cue. These data will permit researchers to take into account the a priori associative strength between cues and targets at these two levels of processing.

A number of experimental tasks within the areas of human learning/memory and information processing involve comparisons of performance across different types of word attributes, often phonemic and semantic. The present research was designed to provide phonemic (rhyme) and semantic (category member) association norms that will permit researchers to take into account the a priori generative probabilities for words at these two processing levels. This is the first extensive set of phonemic norms yet reported in which the cue was itself a word (see Brown, 1976), although it is noteworthy that Nelson and his colleagues (see Nelson \& McEvoy, 1979) have available a set of norms in which rhymes were generated to auditorily presented wordending cues (e.g., "IME").

Cues were selected such that there would be maximum opportunity for the same responses to be generated in both the phonemic and semantic cue conditions. Accordingly, in addition to the basic table of responses, a second table is presented in which are listed all words appearing as responses to more than one cue. This will be of use to researchers wishing to equate "target" words on all relevant word characteristics by using the same set of targets in the phonemic and semantic conditions. A subsequent analysis using cue-target associative strength as the covariate should isolate the effects due to the phonemic and semantic conditions.

This research was supported by an internal grant from Wilfrid Laurier University and Natural Sciences and Engineering Research Council (Canada) Grant A7454 to the author. Requests for reprints should be sent to Keith D. Horton, Department of Psychology, Wilfrid Laurier University, Waterloo, Ontario N2L 3C5, Canada. The author wishes to express thanks to R. P. Fisher and D. L. Nelson for providing unpublished norms used in Fisher and Craik (1977) and Nelson and McEvoy (1979), respectively. Thanks are also due to the various course instructors who permitted access to the groups of subjects during class time and to D. R. Maxwell and P. Beaudoin, who assisted in the data collection.

\section{METHOD}

Subjects

The subjects were 308 undergraduates from Wilfrid Laurier University and the University of Waterioo. Six test sessions were run during regular introductory psychology class times with groups ranging in size from 25 to 125 . Three groups $(n=182)$ were assigncd to the phonemic generation condition, and three $(n=126)$ to the semantic generation condition. The data from four subjects were discarded, two for failure to follow instructions and two because of experimenter error.

\section{Materials}

Each subject was given two booklets (approximately $4.5 \mathrm{x}$ 8.5 in.), each containing 38 pages. On the left side of each page was a single word (phonemic condition) or a phrasc denoting a semantic category (semantic condition). These items are designated as "cues." On the right side of the page were six blank lines arranged vertically. The 76 cues for both the phonemic and semantic conditions were selected from a variety of sources and were randomly ordered for each subject. The rhyme cues were selected so as to include all those for which rhymes were available, yet at the same time, avoiding repetitions. The semantic cues were then selected from a larger pool so as to maximize the likelihood of subjects' generating items that were also likely responses to the rhyme cues. This involved a judgment on the part of the researcher, but it was based in part on a survey of responses in other sets of semantic norms.

\section{Procedure}

All subjects were initially distributed the two booklets and asked to identify themselves as male or female and to put their initials on the back of each booklet. The instructions indicated that the experiment was designed to measure the strength of the relationship between words. The task was to write in the allotted time as many words as possible that exhibited a rhyme (phonemic) or categorical (semantic) relationship to the word or phrase on each successive page. These words were to be written in the order in which they were generated, beginning on the top line.

A period of $10 \mathrm{sec}$ was allotted for the generation of responses to each cue. At the end of each $10 \mathrm{sec}$ interval, the experimenter said, "Now," at which time the subjects were to complete the word they were currently writing and immediately turn the page and commence responding to the next cue. After the first booklet was completed, a break of 1-2 min was interpolated. After the second booklet was completed, subjects were debriefed.

\section{RESULTS}

The data are tabulated in two tables that are available at no cost from the author. In addition, details of the scoring criteria used will be distributed with copies of the tables. The first table is a listing of all responses provided by the subjects. Presented are the first responses for males and females separately, the total number of occurrences of each response regardless of ordinal output position for males and females separately, and the total number of occurrences of each response combined across output position and sex of the respondent. This breakdown of the data is provided for all responses having a frequency of 10 or greater. For response fre- 
quencies less than 10 , the items are simply listed alphabetically with the frequency value. In addition, for the convenience of the user, the data for three commonly used word characteristics are presented with each response having a frequency of 10 or greater: Frequency (f) values are taken from Kucera and Francis (1967), imagery (I) ratings are from the Paivio, Yuille, and Madigan (1968) norms, and pleasantness (Pls) ratings are from the Toglia and Battig (1978) norms. A blank on any of these three measures indicates that the word did not appear in the cited norms or that the response was a composite word.

The second table is a listing of each word given as a response to more than one cue. Provided are (1) the cues eliciting the response, (2) the condition (phonemic or semantic), (3) the page numbers from Table 1 on which each response occurs, and (4) the frequency of the response to each cue.

\section{REFERENCES}

Brown, A. S. Catalog of scaled verbal material. Memory \& Cognition, 1976, 4(Supplement), 1S-45S.

Fisher, R. P., \& Chaik, F. I. M. Interaction between encoding and retrieval operations in cued recall. Journal of Experimental Psychology: Human Learning and Memory, 1977, 3, 701-711.

Kucera, H., \& Francis, W. N. Computational analysis of present-day American English. Providence, R.l: Brown University Press, 1967.

Nelson, D. L., \& McEvoy, C. L. Encoding context and set size. Journal of Experimental Psychology: Human Learning and Memory, 1979, 5, 292-314.

Paivio, A., Yuille, J. C., \& Madiana, S. A. Concreteness, imagery, and meaningfulness values for 925 nouns. Journal of Experimental Psychology Monograph Supplement, 1968, 76(Whole No. 1, Pt. 2), 1-25.

Toolia, M. P., \& BATTIG, W. F. Handbook of semantic word norms. Hillsdale, N.J: Erlbaum, 1978.

(Received for publication July 6, 1982; revision accepted November 27, 1982.) 